\title{
The effect of water stress on phenological and ecophysiolog- ical characteristics of cheatgrass and Sandberg's bluegrass
}

\author{
STEVEN O. LINK, GLENDON W. GEE, AND JANELLE L. DOWNS
}

\section{Abstract}

Comparative field studies of cheatgrass (Bromus tectorum L.) with Sandberg's bluegrass (Poa sandbergii Vasey) were conducted to further our understanding of the plant characteristics that contribute to success in habitats where water is a limiting factor. To evaluate the effect of soil water on phenological development, stomatal conductance, and xylem pressure potential of these grasses, observations were made in the field for $\mathbf{2}$ growing seasons (1986 and 1987). Stomatal conductance, transpiration, and xylem pressure potential data, gathered as soils dried during 1986, indicated that water stress developed earlier and to a greater degree in Sandberg's bluegrass than in cheatgrass. Xylem pressure potential was lower in Sandberg's bluegrass than in cheatgrass, and the difference increased throughout the growing season. Stomatal conductance and transpiration were greater for cheatgrass than for Sandberg's bluegrass. Maintenance of high soil water potentials by irrigating through the 1987 growing season retarded phenological development and delayed senescence by about 10 days for both species. Predawn xylem pressure potential for irrigated plants remained higher than for nonirrigated plants; however, as the plants senesced, xylem pressure potential also decreased in the nonstressed plants.

Key Words: Bromus tectorum, Poa sandbergii, stomatal conductance, xylem pressure potential, phenology

The introduction of cheatgrass (Bromus tectorum $\mathrm{L}$.), a winter annual, to the semiarid Columbia Plateau of North America has radically changed the plant community structure of the region (Hulbert 1955, Daubenmire 1970, Mack 1981). Cheatgrass dominates areas where soil has been disturbed by agronomic practices (Daubenmire 1970, Rickard 1985). Once cheatgrass becomes established, it prevents the native plants from establishing by successfully competing for water. Vigorous winter root growth of cheatgrass allows it to dominate the soil water reserve by the time plants become stressed by low water potentials in the spring and early summer (Harris 1967).

Although cheatgrass competition with range plants such as bluebunch wheatgrass (Agropyron spicatum Pursh) (Hulbert 1955, Klemmendson and Smith 1964, Harris 1967) has been studied extensively, less attention has been given to its interactions with other species in native communities. Cheatgrass has relegated to minor status species such as California brome (Bromus carinatus Hook and Arm.), sixweek's fescue (Festuca octoflora WaH.), and F. microstachys Nutt. (Mack 1981) of the shrub-steppe region of the Columbia Plateau. Cheatgrass can now be found throughout nonagricultural areas of the Columbia Plateau, and it continues to invade new areas (Daubenmire 1970).

Many of the drier portions of the Columbia Plateau are codominated by cheatgrass and Sandberg's bluegrass (Poa sandber-

\footnotetext{
Authors are research scientist, senior staff scientist, and specialist, Earth and Environmental Sciences Center, Pacific Northwest Laboratory, Richland, Washington 99352.

Research was funded by the U.S. Department of Energy under Contract DE-AC0676RLO 1830.

Authors wish to thank Drs. R. Al Black, G.S. Campbell, M.J. Fayer, and W.H

Rickard for assistance in preparing the manuscript

Manuscript accepted 8 March 1990
}

gii Vasey), which is perennial and dormant in the summer (Daubenmire 1970, Rickard 1975). In areas of sand dune knob and kettle topography, cheatgrass dominates south-facing slopes, whereas Sandberg's bluegrass dominates north-facing slopes (Rickard 1975). The south-facing slopes receive higher levels of solar radiation and thus are drier than the north-facing slopes (Hinds 1975). Cheatgrass may adapt better to the warm, dry microclimates of the south-facing slopes than Sandberg's bluegrass.

In level areas of the sand dunes where our research was conducted, cheatgrass remained green longer into the spring drought period than Sandberg's bluegrass. Because Sandberg's bluegrass is dominant on north-facing slopes, we hypothesized that maintaining high soil water potentials would allow Sandberg's bluegrass to continue growth and activity further into the growing season than cheatgrass.

The purpose of this field study was to: (1) compare the water relations of these 2 species under increasing water stress and (2) determine how the availability of soil water affects phenological development and xylem pressure potential.

\section{Materials and Methods}

\section{Study Area}

The study site $119^{\circ} 20^{\prime} 00^{\prime \prime} \mathrm{W}, 46^{\circ} 24^{\prime} 20^{\prime \prime} \mathrm{N}$ ), located on the U.S. Department of Energy's (DOE) Hanford Site in southeastern Washington, has cool, wet winters and hot, dry summers. The average annual precipitation is $16 \mathrm{~cm}$ (Stone et al. 1983), most of which occurs in fall and winter. The terrain at the study site is flat, and one soil type is present, a Typic Torripsamment (Hajek 1966). This soil has relatively low water-holding capacity; neutron probe measurements showed an average difference of only $0.04 \mathrm{~cm}^{3} \mathrm{~cm}^{-3}$ soil water content between wet (early spring) and dry (late fall) conditions over a $3-\mathrm{m}$ deep profile. The surface (top $45 \mathrm{~cm}$ ) is a loamy sand ( $79 \%$ sand, $17 \%$ silt, $4 \%$ clay), while the soil below 45 $\mathrm{cm}$ is a coarse sand ( $92 \%$ sand, $5 \%$ silt, $3 \%$ clay) (Gee and Kirkham 1984). This area was burned by range fire in August 1984. Dominant species of the community are Sand berg's bluegrass and cheatgrass, with canopy coverage of $30 \%$ and $20 \%$, respectively. Previous sampling of the area (Gee and Kirkham 1984) demonstrated that soils and plant cover were consistently similar over a several hectare area. Draba verna L. and Tragopogon dubious Scop. also occur as well as lichens and mosses covering the inter-plant spaces.

\section{Treatments}

Sampling and observations were conducted within the homogeneous study area in 2 phases. In the initial phase conducted during the growing season of 1986 , plants were randomly chosen within the study area to measure stomatal conductance, transpiration, and xylem pressure potential; record phenological stage; and destructively sample the roots and shoots. Soil moisture samples were taken adjacent to the individual plants selected for water relations measurements.

In the second phase of the study during the 1987 growing season, a 1-m by $10-\mathrm{m}$ plot was irrigated on a weekly schedule using a drip irrigation system. Plants were randomly chosen both within and outside the irrigated plot to compare water relations of the 2 
species under differing soil water conditions. Soil cores were taken adjacent to the plants selected to determine the soil water conditions for that sample. Although the study area is homogeneous (Gee and Kirkham 1984), allowing this simple experimental design, we do not draw the conclusion that these species will respond the same way in other habitats.

\section{Measurements and Sampling Procedures}

The initial phase of this study focused on evaluating diurnal patterns of stomatal conductance, leaf transpiration, and xylem pressure potential. These water relations parameters were assessed 3 times between early April and early May 1986 . Four replicates of each species, randomly chosen, were monitored approximately every 2 hours from before sunrise until sunset. The xylem pressure potential of green leaves or shoots was measured with a pressure bomb. A damp tissue was placed in the pressure chamber to reduce the effects of desiccation, and samples were slowly pressurized immediately after stems were cut.

Stomatal conductance and transpiration were measured using a LI-1600 steady-state porometer. Stomatal conductance and transpiration were estimated for partial canopies of both species. The amount of leaf material included in the leaf chamber during measurements was such that the porometer could achieve a null balance at ambient relative humidity. The youngest 3 leaves on each stem of cheatgrass and a portion of intact canopy of Sandberg's bluegrass were used. Single-sided leaf area was estimated by measuring blade and stem widths and lengths. Air temperature, photosynthetically active radiation (PAR), and relative humidity were also measured concurrently.

Root and shoot observations were made by excavating and measuring a range of sizes of plants at every observation period. The roots were separated from the soil by soaking and careful spraying. Some root material was lost, but it consisted primarily of dead roots of Sandberg's bluegrass and the fine roots of cheatgrass. Live roots of Sandberg's bluegrass were separated from dead roots by inspection under a stereo-microscope. Live roots were white to brown and turgid, while dead roots were dark brown and shriveled. Roots of the 2 species were easily separated when they occurred in the same sample. Roots of cheatgrass were relatively thin with little branching while those of Sandberg's bluegrass were relatively thick and were significantly more branched. The oven-dried biomass of live roots was determined in $10-\mathrm{cm}$ deep increments. The ovendried biomass of green shoot material was determined, and the root/shoot ratio based on the oven-dried biomass of live material. At the conclusion of the experiment, a trench was dug to determine the greatest rooting depth within the soil profile. Greatest rooting depth was determined in the trench because the deepest roots easily could be lost in the process of excavation of whole plants.

Gravimetric soil water content was determined over 4 depth ranges ( 0 to 10,10 to 20,20 to 30 , and 30 to $40 \mathrm{~cm}$ ) by taking 3 replicate soil cores adjacent to each species. The soil samples were weighed and then dried at $105^{\circ} \mathrm{C}$ for at least 2 days before reweighing to determine dry weight.

During the second phase in 1987, water was added to a $1-\mathrm{m}$ by 10-m plot to evaluate phenology and xylem pressure potential of the 2 species when the soils were maintained at high water potentials. Water was applied weekly by drip irrigation from 15 April until 9 June. Soil water potential values, measured using tensiometers, were greater than $-0.03 \mathrm{MPa}$ throughout the root zone during the period. Gravimetric water content and soil water potential data were also obtained throughout the investigation period from random samples outside the irrigated area. Soil samples were collected and soil water potential measured with a ceramic-coated thermocouple psychrometer using a Decagon SC-10 sample changer (See Rawlins and Campbell 1986, p. 614). Using this method of applying a water droplet on the ceramic bead and measuring the effective wet-bulb depression allows for measurements of water potentials as low as $-300 \mathrm{MPa}$. Three replicate samples were collected at 6 depth ranges $(0-5,5-10,10-20,20-30,30-40$, and $40-50 \mathrm{~cm})$.

Phenology and predawn xylem pressure potential data were collected from late February until 9 June in the nonirrigated and irrigated areas. Phenology observations were classified into phenophases following the convention of French and Sauer (1974) for short grass prairie species (Table 1).

Table 1. Definitions of 14 phenophases for short grass prairie species after French and Sauer (1974).
1. Pre-emergence growth/winter domancy
2. First visible growth
3. First leaves fully expanded
4. Middle leaves fully visible
5. First leaves senescent; middle leaves fully expanded
6. Late leaves fully expanded
7. Developing floral buds; middle-late vegetative
8. Mature floral buds; late vegetative
9. Floral buds and open flowers
10. Buds, flowers, and green fruit
11. Buds, flowers, green fruit, and ripe fruit
12. Green fruit and ripe fruit
13. Ripe fruit and dispersing seeds
14. Flowering-induced dormancy

\section{Results}

Diurnal Patterns of Stomatal Conductance, Leaf Transpiration, and Xylem Pressure Potential

Diurnal water relation patterns observed in 1986 are compared in Figures 1 to 3 for both species. April 11 was a cloudy, cool day with the vapor pressure deficit (VPD) rising to $13 \mathrm{mb}$ (Fig. 1a, b, and c). Data collection stopped at 1400 because of rain. Xylem pressure potential patterns diverged as the day progressed for the 2 species (Fig. 1d). Predawn potentials were near $-0.2 \mathrm{MPa}$ for both species. By 0900, potentials of Sandberg's bluegrass had fallen to $-2.5 \mathrm{MPa}$ and remained there the rest of the day. Potentials of cheatgrass fell only to $-0.8 \mathrm{MPa}$. Stomatal conductance and transpiration were higher for cheatgrass than for Sandberg's bluegrass after 0800 (Fig. le and 1f).

April 18 was a hazy, warm day with the VPD rising to $22 \mathrm{mb}$ (Fig. 2a, b, and c). Xylem pressure potentials for Sandberg's bluegrass were consistently lower than for cheatgrass throughout the day (Fig. 2d). Predawn values for Sandberg's bluegrass were -1.2 $\mathrm{MPa}$, while cheatgrass had values near zero. Minimum values had fallen to $-3.6 \mathrm{MPa}$ for Sandberg's bluegrass and to $-1.6 \mathrm{MPa}$ for cheatgrass by 1400 . Xylem pressure potentials generally began to rise in both species by the end of the day. Stomatal conductance values for Sandberg's bluegrass were consistently lower than those for cheatgrass throughout the day (Fig. 2e). Stomatal conductance declined after 0800 for Sandberg's bluegrass, while little if any midday closure occurred for cheatgrass. For this date, as for 11 April, transpiration rates were consistently lower for Sandberg's bluegrass than for cheatgrass (Fig. 2f).

May 1 was a partly cloudy warm day with the VPD rising to 26 $\mathrm{mb}$ (Fig. 3a, b, and c). By this date, only the inflorescences of Sandberg's bluegrass were still succulent, while the leaves of cheatgrass were still green. Xylem pressure potential values for Sandberg's bluegrass were still consistently lower than those for cheatgrass throughout the day (Fig. 3d). Potential values remained below $-3.0 \mathrm{MPa}$ throughout the day. In contrast, cheatgrass had predawn values near zero falling only to a minimum of $-2.5 \mathrm{MPa}$. Stomatal conductance values for Sandberg's bluegrass remained low throughout the day (Fig. 3e). Stomatal conductance was higher for cheatgrass than for Sandberg's bluegrass with a maxi- 

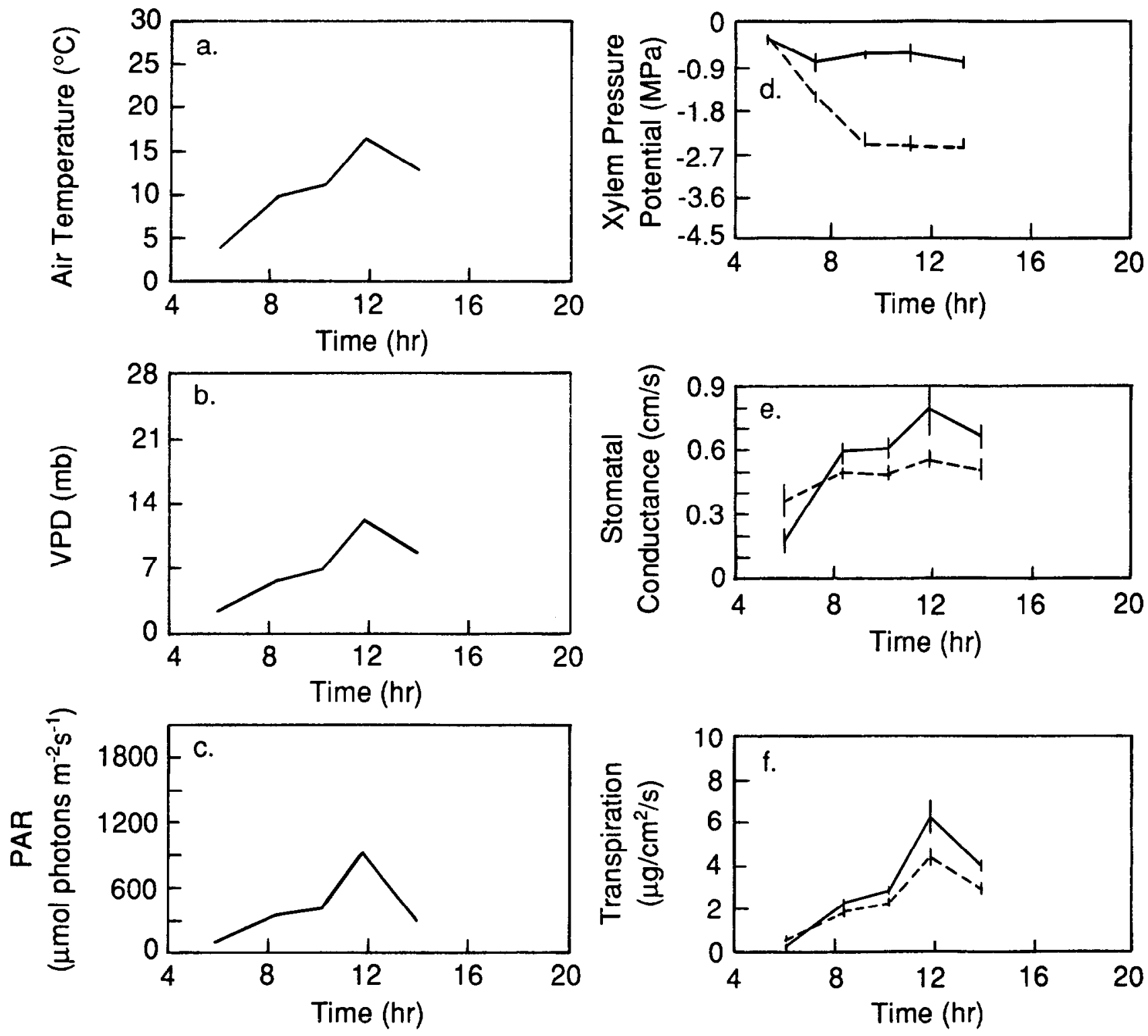

Fig. 1. Diurnal response of cheatgrass and Sandberg's bluegrass on 11 April 1986. Sub-figures are (a) air temperature, (b) vapor pressure deficit (VPD), (c) photosynthetically active radiation (PAR), (d) xylem pressure potential, (e) stomatal conductance, and (f) transpiration. Values are averages. Bars are 1 standard error of the mean ( $n=8$ for $a, b$, and $c ; n=4$ to 7 for $d$; and $n=4$ for $e$ and $f$.

mum value at 0700 . Transpiration rates were low for Sandberg's bluegrass with a maximum occurring at 1300 (Fig. 3f). Transpiration rates of cheatgrass were higher than those of Sandberg's bluegrass, and the maximum also occurred at 1300.

As the spring weather became warmer and drier, both predawn xylem pressure potentials and maximum stomatal conductance of Sandberg's bluegrass decreased (Table 2). In comparison, although maximum stomatal conductance decreased in cheatgrass, predawn xylem pressure potential changed little over the measurement period. Thus, no clear relationship was identified between the predawn xylem pressure potential and the maximum stomtal conductance.

Root/shoot ratios were significantly lower for cheatgrass than for Sandberg's bluegrass. The ratio gradually declined for cheatgrass throughout the season while the ratio for Sandberg's blue-
Table 2. Mean maximal stomatal conductance and predawn xylem pressure potential values for cheatgrass and Sandberg's bluegrass.

\begin{tabular}{llcc}
\hline \hline Species & 1986 & $\begin{array}{c}\text { Mean } \\
\text { maximal } \\
\text { stomatal } \\
\text { conductance } \\
(\mathrm{cm} / \mathrm{s})\end{array}$ & $\begin{array}{c}\text { Mean } \\
\text { predawn } \\
\text { xylem } \\
\text { pressure potential } \\
(-\mathrm{MPa})\end{array}$ \\
\hline Cheatgrass & Apr. 11 & 0.78 & 0.24 \\
& Apr. 18 & 0.68 & 0.11 \\
Sandberg's & May 1 & 0.62 & 0.32 \\
bluegrass & Apr. 11 & 0.54 & 0.16 \\
& Apr. 18 & 0.37 & 1.14 \\
& May 1 & 0.10 & 3.40 \\
\hline
\end{tabular}



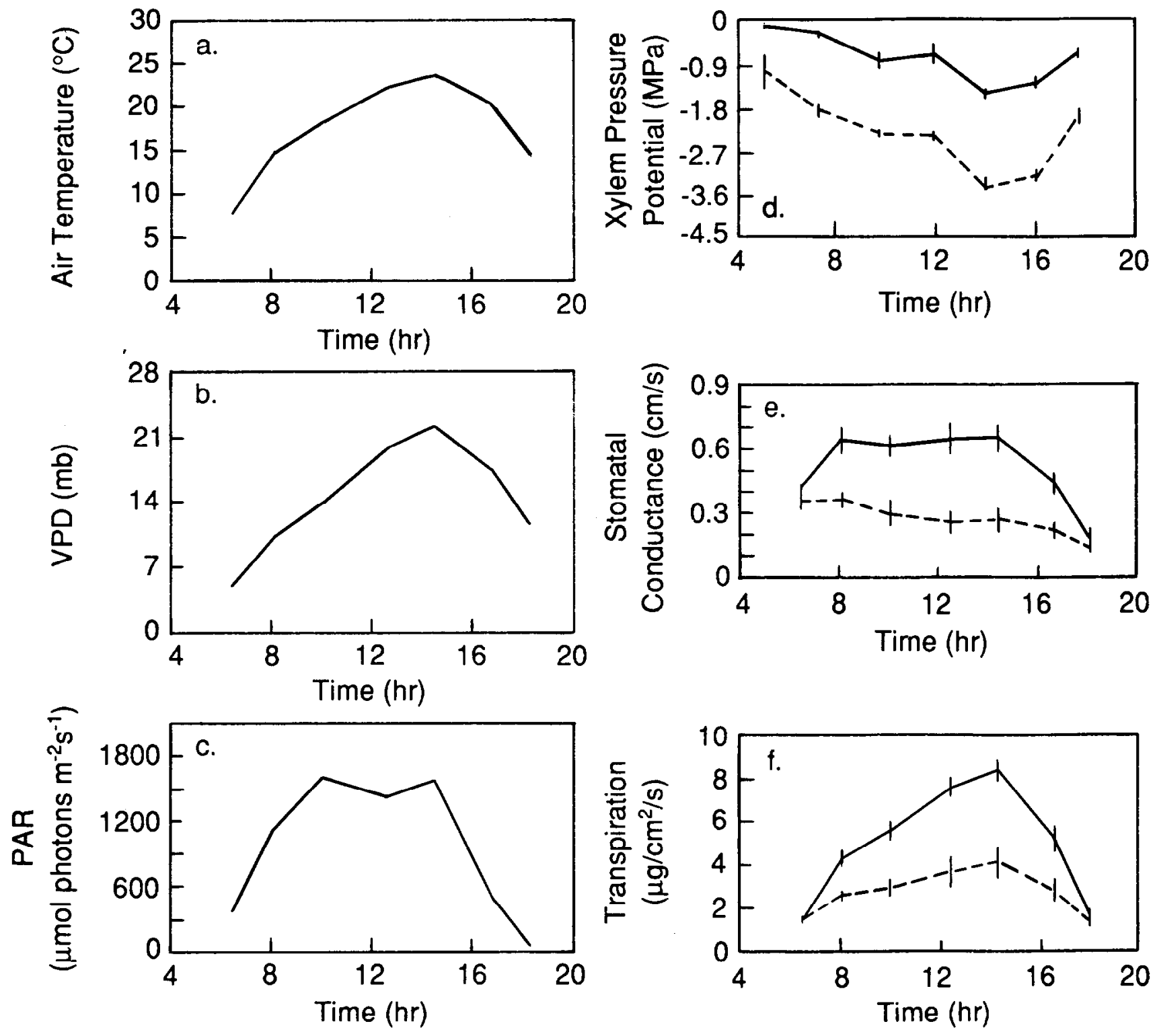

Fig. 2. Diumal response of cheatgrass and Sandberg's bluegrass on 18 April 1986. Sub-figures are the same as described for Figure 1.

grass decreased only at the end of the period (Fig. 4). The greatest depth of roots observed for large individuals of cheatgrass was 45 to $50 \mathrm{~cm}$, which reaches into the coarse sand zone of the profile. The greatest depth observed for large individuals of Sandberg's bluegrass was $35 \mathrm{~cm}$. The majority of the root mass occurred in the top $10 \mathrm{~cm}$ of the soil for both species. Little root mass was found below $20 \mathrm{~cm}$.

Gravimetric soil water content generally decreased with depth and as the season progressed (Fig. 5). Water content at the $5-\mathrm{cm}$ depth increased slightly on day 82 and was lower than at other depths on day 111 .

\section{The Effect of Soil Water on Phenology and Xylem Pressure Potential}

Observations in 1987 indicated that phenological development of both species in the irrigated plot was retarded by one stage compared with plants in the nonirrigated plot. This difference in phenological progression became observable for both species 2 weeks after initial irrigation (Figs. 6a and b). Although both species in the nonirrigated plot were totally senescent by late May, total senescence for plants in the irrigated plot was delayed until 9 June. Phenological development of cheatgrass was always behind that of Sandberg's bluegrass, whether irrigated or not, with the difference between the species becoming smaller by the end of the season.

Predawn xylem pressure potential values decreased through the spring for both species in both treatments (Fig. 7). Predawn values were always the lowest for Sandberg's bluegrass in the nonirrigated plot with values undetectable by 9 May. Values for irrigated individuals of Sandberg's bluegrass were generally lower than those for nonirrigated individuals of cheatgrass. Irrigated Sandberg bluegrass and nonirrigated cheatgrass had predawn xylem pressure potentials too low to measure by $18 \mathrm{May}$. Irrigated cheatgrass consistently had the highest predawn xylem pressure potential throughout the period with values dropping rapidly only after 18 

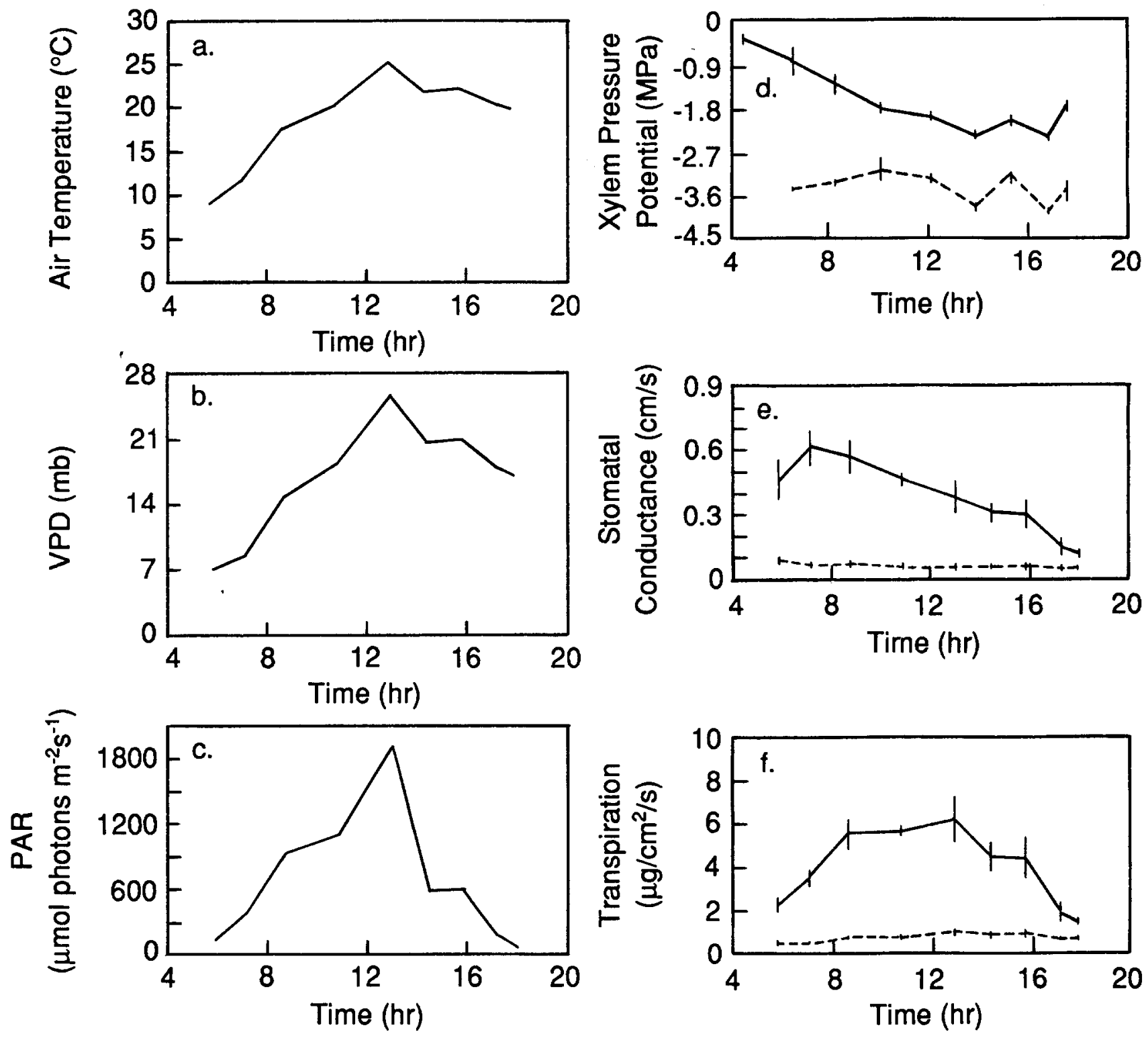

Fig. 3. Diurnal response of cheatgrass and Sandberg's bluegrass on 1 May 1986. Sub-figures are the same as described for Figure 1.

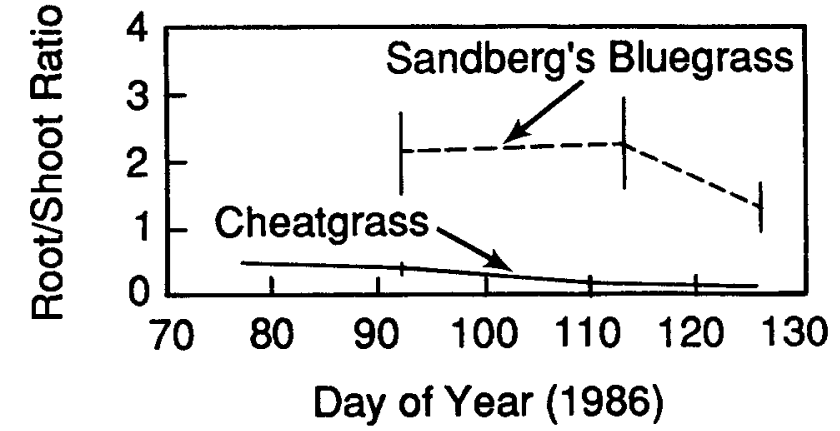

Fig. 4. Root/Shoot ratio of cheatgrass and Sandberg's bluegrass. The ratio is based on the oven-dried biomass of live roots and green shoots. Bars are 1 standard error of the mean $(n=5$ to 13 for cheatgrass; and $n=3$ to 5 for Sandberg's bluegrass).
May. Values became undetectable by 9 June. Irrigating to maintain high soil water potential delayed loss of water uptake capability by 10 days for Sandberg's bluegrass and by 20 days for cheatgrass.

Soil water in the nonirrigated plot was expressed gravimetrically and as water potential (Fig. 8a and b). High soil water potentials were maintained in the irrigated area as evidenced by tensiometer values greater than $-0.03 \mathrm{MPa}$ throughout the profile during the period. The gravimetric pattern of soil water shows the rapid drying of the upper soil layers relative to the deeper layers as the season progressed. By 22 April, water content was less than 5\% through the profile and eventually fell to about $2 \%$ by 19 May. Rainfall in early June increased the water content to about $4 \%$. Soil water potential values decreased from 15 April through 28 May and increased by 9 June after rains. Minimum soil water potential was $-45 \mathrm{MPa}$ at $2.5 \mathrm{~cm}$ and $-4 \mathrm{MPa}$ at $25 \mathrm{~cm}$ on $4 \mathrm{May}$. Even drier conditions were observed by late May, but because of technical 


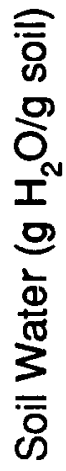

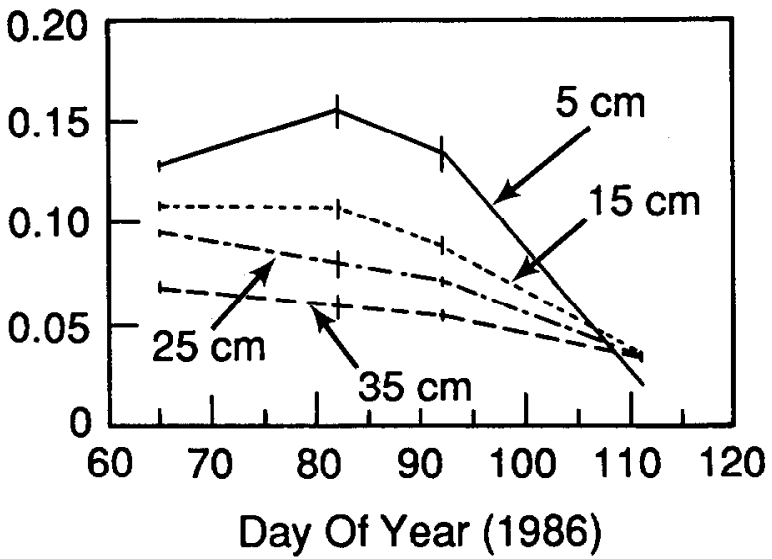

Fig. 5. Average gravimetric soil water content $(\%)$ as a function of time with depth. Bars are 1 standard error of the mean $(n=6)$.
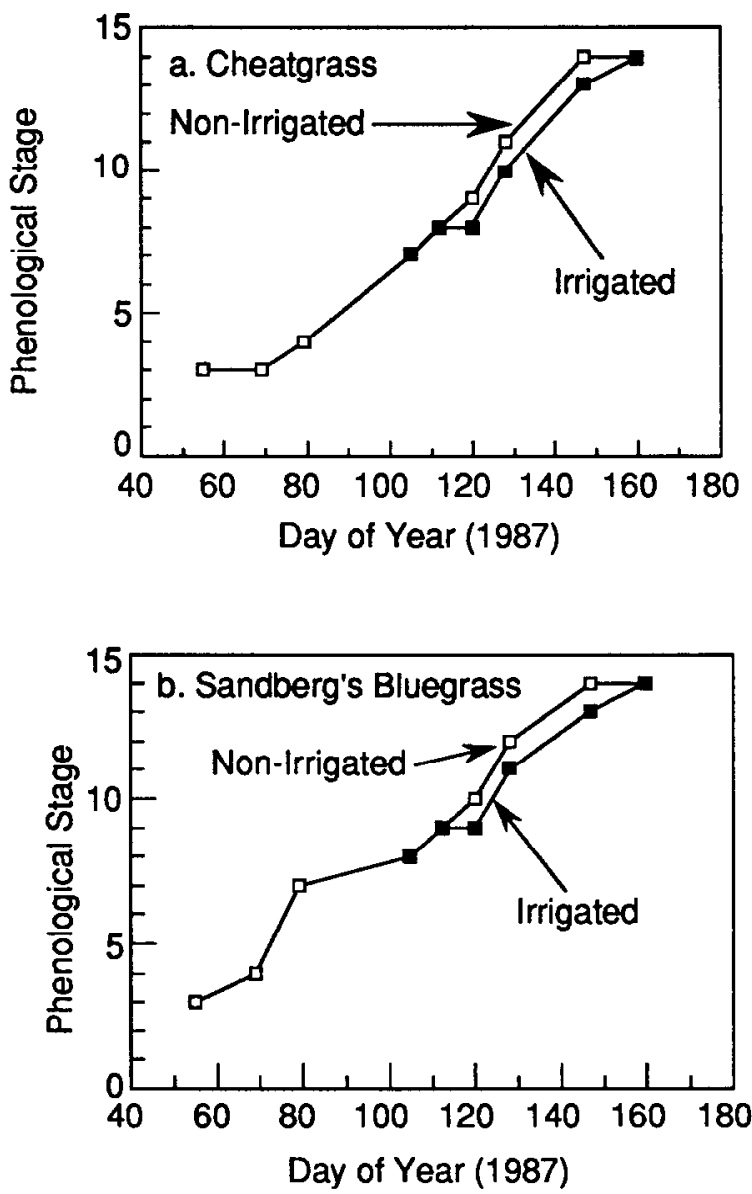

Fig. 6. Phenological stage of (a) cheatgrass and (b) Sandberg's bluegrass in irrigated and nonirrigated plots. Phenological stages are defined in Table 1.

problems, we could not obtain values of soil water potential.

Discussion

In arid environments, where plants depend on stored soil water, competitive success depends, in part, on rooting depth and root phenology. Deeper-rooted species generally suffer less from drought

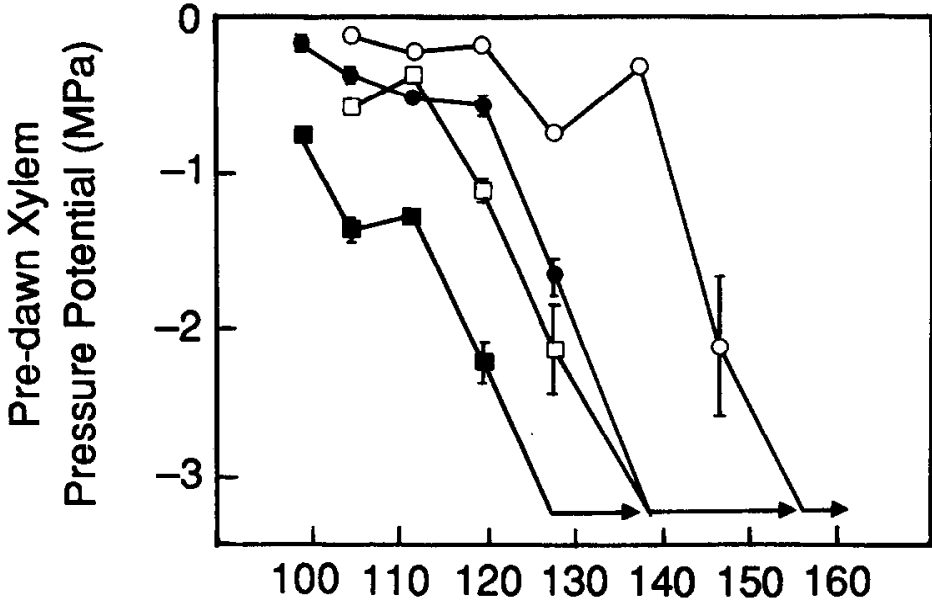

Day of Year (1987)

Fig. 7. Predawn xylem pressure potential of cheatgrass in irrigated ( 0 ) and nonirrigated $(\bullet$ ) plots and of Sandberg's bluegrass in irrigated ( $\square$ ) and nonirrigated ( $\square$ ) plots. Bars are 1 standard error of the mean ( $n=4$ to 6).
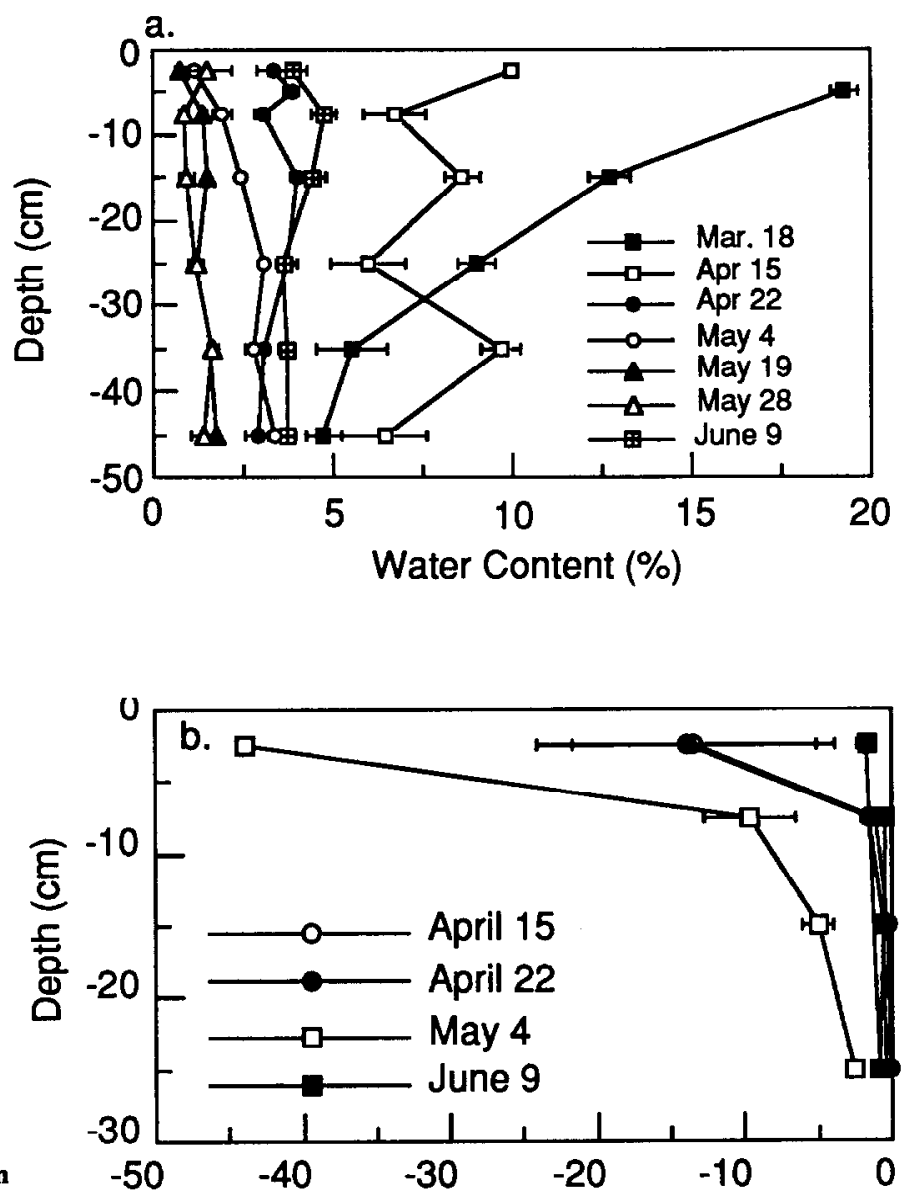

Soil Water Potential (MPa)

Fig. 8. Average percent (a) gravimetric soil water content and (b) average soil water potential with depth in nonirrigated plots from 18 March to 9 June 1987. Bars are 1 standard error of the mean $(n=3)$. 
than shallower rooted species (Kramer 1983). Species that have relatively greater root growth during the winter months can preempt the soil water resource compared with species that have a more retarded root phenology (Harris 1977). Harris (1967) reported that cheatgrass seedlings were more competitive for soil water because of greater root growth rates in the winter months than crested wheatgrass [Agropyron desertorum (Fisch.) Schult.] and bluebunch wheatgrass seedlings. Although we did not perform controlled competition experiments, we observed that cheatgrass was active later into the summer dry season than Sandberg's bluegrass. The deeper roots of cheatgrass allow it access to soil water when the shallower-rooted Sandberg's bluegrass can not.

Sandberg's bluegrass developed water stress earlier than did cheatgrass. Stomatal conductance, transpiration, and xylem pressure potential values of Sandberg's bluegrass were less than those of cheatgrass with the difference becoming greater as the season progressed. Reductions in stomatal conductance during the day occurred earlier in the season for Sandberg's bluegrass than for cheatgrass, which indicates differential development of water stress. Diurnal stomatal conductance of cheatgrass and Sandberg's bluegrass exhibit patterns of stomatal closure similar to those found in other studies (Tenhunen et al. 1982, Losch et al. 1982, Hesla et al. 1985) with increasing water stress.

The relationship between the maximum stomatal conductance and predawn xylem pressure potential for Sandberg's bluegrass was similar to that found in scherophyll species experiencing moderate water stress (Tenhunen et al. 1982). Our results suggest that predawn xylem pressure potential is a strong determinant of the potential conductance independent of other diurnally varying variables.

Our results also show that available soil water affects phenology. The timing of phenological stage of the 2 species was different: Sandberg's bluegrass initiated and completed aboveground growth and seed set earlier than did cheatgrass when experiencing normal soil water conditions. Phenological development was retarded in both species when soil water potentials were maintained. This effect has been identified as a major factor in the development of senescence in shortgrass prairie plants (Dickinson and Dodd 1976). Long day length also induces dormancy in Sandberg's bluegrass (Hironaka and Tisdale 1973). The relative contributions of day length and water stress to phenological development for cheatgrass and Sandberg's bluegrass are not known. We demonstrated that maintaining high soil water potentials retards phenological development in these 2 species, but does not prevent senescence.

Availability of soil water, root factors, and phenology play a significant role in the observed difference in the development of water stress between Sandberg's bluegrass and cheatgrass. Greatest root depth was different in these species. Roots of Sandberg's bluegrass extended to only $35 \mathrm{~cm}$; cheatgrass roots were less concentrated, but extended to at least $45 \mathrm{~cm}$ for larger individuals. In general, shallow-rooted species suffer more from drought than do deep-rooted species (Kramer 1983). In the soils at this study site, water potential increased with increasing depth. The evidence suggests that deeper roots of cheatgrass allow the plant to obtain water later in season than can Sandberg's bluegrass, thus allowing cheatgrass to remain active longer. The greater root/shoot ratio of Sandberg's bluegrass did not enhance its ability to extract water relative to cheatgrass because the majority of the roots were in the top $20 \mathrm{~cm}$ of the soil, which dried earlier in the season.

Predawn xylem pressure potential usually is expected to be close to that of the soil in the wettest soil zone containing roots (Jones 1977). A strong correlation between predawn xylem pressure potential and soil water potential was found for bluegrama [Bouteloua gracilis (H.B.K.) Lag.] $\left(r^{2}=0.92\right)$, a perennial grass of the shortgrass steppe of Colorado (Sala et al. 1981) and for Pappopho- rum subbulbosum Arech. $\left(r^{2}=0.94\right)$, a warm-season perennial grass of the semiarid areas of Argentina (Distel and Fernandez 1987). Such a strong relationship was not found in our study. A possible explanation may be that phenology affected the predawn xylem pressure potential. A low correlation between these variables may be characteristic of cool-season grasses such as Sandberg's bluegrass and cheatgrass. Distel and Fernandez (1987) found a low correlation $\left(r^{2}=0.4\right)$ for Stipa tenuis Phil. and Piptochaetium hapostaense (Speg.) Hack, which are cool-season grasses. We found that although predawn xylem pressure potential values were higher for irrigated plants than for nonirrigated plants, the predawn water potential values for plants receiving irrigation were still lower than water potentials of the soil in the irrigated plot. As phenological stage advances, both of these species experience reductions in the ability to absorb or conduct water, leading to increasing lower values of predawn xylem pressure potential.

\section{Conclusion}

Our hypothesis that Sandberg's bluegrass would remain active longer than cheatgrass when high water potentials were maintained in the soil proved false. The dominance of Sandberg's bluegrass on north-facing slopes observed by Rickard (1975) is not a direct result of the influence of soil water conditions on phenology and plant water status and probably depends on other abiotic and biotic factors. We observed that water stress develops earlier in the season for Sandberg's bluegrass than for cheatgrass. The development of earlier water stress in Sandberg's bluegrass was characterized by a more advanced phenological development and lower values of xylem pressure potential, stomatal conductance, and transpiration than observed in cheatgrass. When soil water was not limiting, senescence was delayed, but not prevented; and predawn xylem pressure potential values were lower. Thus, although soil water must play a role in the differential development of water stress for these species, other factors that drive phenological development also contribute to the development of water stress.

\section{Literature Cited}

Daubenmire, R. 1970. Steppe vegetation of Washington. Wash. Agr. Exp. Sta. Tech. Bull. 62:1-131.

Dickinson, C.E., and J.L. Dodd. 1976. Phenological pattern in the shortgrass prairie. Amer. Midland Natur. 96:367-378.

Distel, R.A., and O.A. Fernandez. 1987. Leaf water potential trends in three grasses native to semiarid Argentina. J. Range Manage. 40:203-207.

French, N., and R.H. Sauer. 1974. Phenological studies and modeling in grasslands, Vol. 8:227-236. In: J. Jacobs, O.L. Lange, J.S. Olson, and W. Wiesser (eds.), Phenology and seasonality modeling, Springer-Verlag, New York.

Gee, G.W., and R.R. Kirkham. 1984. Arid site water balance: evapotranspiration modeling and measurements. PNL-5177, Pacific Northwest Laboratory, Richland, Wash.

Hajek, B.F. 1966. Soil Survey-Hanford Project in Benton County, Washington. BNWL-243, Pacific Northwest Laboratory, Richland, Wash.

Harris, G.A. 1967. Some competitive relationships between Agropyron spicatum and Bromus tectorum. Ecol. Mono. 37:89-111.

Harris, G.A. 1977. Root phenology as a factor of competition among grass seedlings, p. 93-99. In: J.K. Marshall (ed.), The belowground ecosystem: A synthesis of plant-associated processes. Colorado State Univ., Ft. Collins.

Hesla, B.I., H.L. Tieszen, and T.W. Boutton. 1985. Seasonal water relations of Savannah shrubs and grasses in Kenya, East Africa. J. Arid Environ. 8:15-31.

Hinds, W.T. 1975. Energy and carbon balance in cheatgrass: an essay in autecology. Ecol. Mono. 45:367-388.

Hironaka, M., and E.W. Tisdale. 1973. Growth and development of Sitanion hystrix and Poa sandbergii. U.S. Inter. Biol. Prog. Desert Biome RM 73:16:1-17.

Hulbert, L.C. 1955. Ecological studies of Bromus tectorum and other annual bromegrasses. Ecol. Mono. 25:181-213. 
Jones, H.G. 1977. Aspects of the water relations of spring wheat (Triticum aestivum L.) in response to induced drought. J. Agr. Sci. Camb. 88:267-282.

Klemmendson, J.O., and J.G. Smith. 1964. Cheatgrass (Bromus tectorum L.). The Bot. Rev. 30:226-262.

Kramer, P.J. 1983. Water relations of plants. Academic Press, New York.

Losch, R., J.D. Tenhunen, J.S. Pereira, and O.L. Lange. 1982. Diurnal courses of stomatal resistance and transpiation of wild and cultivated Mediterranean perennial at the end of the summer dry season in Portugal. Flora 172:138-160.

Mack, R.N. 1981. Invasion of Bromus tectorum L. into western North America: an ecological chronical. Agro-Ecosystems 7:154-165.

Rawlins, S.L., and G.S. Campbell. 1986. Soil water potential measurements, p. 597-618. In: Methods of soil analysis. Part 1, Monograph 9, Amer. Soc. Agron., Madison, Wisc.
Rickard, W.H. 1985. Shoot production and mineral nutrient assimilation in cheatgrass communities. Northw. Sci. 59:169-179.

Rickard, W.H. 1975. Vegetation of knob and kettle topography in SouthCentral Washington. Northw. Sci. 49:147-152.

Sala, O.E., W.K. Lauenroth, W.J. Parton, and M.J. Trlica. 1981. Water status of soil and vegetation in a shortgrass steppe. Oecologia 48:327-331.

Stone, W.A., J.M. Thorp, O.P. Gifford, and D.J. Hoitink. 1983. Climatological summary for the Hanford area. PNL-4622, Pacific Northwest Laboratory, Richland, Wash.

Tenhunen, J.D., O.L. Lange, and D. Jahner. 1982. The control of atmospheric factors and water stress of midday stomatal closure in Arbutus unedo growing in a natural macchia. Oecologia 55:165-169. 